

\section{DISCLAIMER}

Portions of this document may be illegible in electronic image products. Images are produced from the best available original document. 


\title{
Epitaxial $\mathrm{Pb}\left(\mathrm{Zr}_{\mathrm{x}} \mathrm{Ti}_{1-\mathrm{x}}\right) \mathrm{O}_{3} / \mathrm{SrRuO}_{3}(\mathrm{x}=0,0.35,0.65)$ multilayer thin films on $\mathrm{SrTiO}_{3}(100)$ and $\mathrm{MgO}(100)$ prepared by MOCVD and $\mathrm{RF}$ sputtering
}

\author{
C. M. Foster, R. Csencsits, P. M. Baldo, G. R. Bai, Z. Li, and L. E. Rehn \\ Materials Science Division, Argonne National Laboratory \\ 9700 S. Cass Avenue, Argonne, IL 60439 \\ L. A. Wills and R. Hiskes \\ Hewlett Packard Laboratories, Hewlett-Packard Company \\ 3500 Deer Creek Road, Palo Alto, CA 94304
}

\begin{abstract}
Epitaxial $\mathrm{SrRuO}_{3}$ thin films were deposited on $\mathrm{SrTiO}_{3}(100)$ and $\mathrm{MgO}(100)$ substrates by. RF sputtering for use as bottom electrodes and epitaxial buffer layers. On these conductive substrates, epitaxial $\mathrm{Pb}\left(\mathrm{Zr}_{\mathrm{x}} \mathrm{Ti}_{1-\mathrm{x}}\right)_{3}(\mathrm{PZT} ; \mathrm{x}=0.35,0.65)$ and $\mathrm{PbTiO}_{3}(\mathrm{PT} ; \mathrm{x}=0)$, thin films were deposited by metalorganic chemical vapor deposition (MOCVD). X-ray diffraction (XRD), RBS channeling (RBS), transmission. electron microscopy (TEM) and optical waveguiding were used to characterize the phase, microstructure, defect structure, refractive index, and film thickness of the deposited films. The PZT and PT films were epitaxial and c-axis oriented. $90^{\circ}$ domains, interfacial misfit dislocations and threading dislocations were the primary structural defects, and the films showed as high as a 70\% RBS channeling reduction. Ferroelectric hysteresis and dielectric measurements of epitaxial PZT ferroelectric capacitor structures formed using evaporated Ag top electrode showed:'a remanent polarization of $46.2 \mu \mathrm{C} / \mathrm{cm}^{2}$, a coercive field of $54.9 \mathrm{kV} / \mathrm{cm}$, a dielectric constant of 410 , a bipolar resistivity of $\sim 5.8 \times 10^{9} \Omega-\mathrm{cm}$ at a field of $275 \mathrm{kV} / \mathrm{cm}$, and a breakdown strength of $>400 \mathrm{kV} / \mathrm{cm}$. Cyclic fatigue measurements showed that the remanent polarization was maintained for $>10^{9}$ cycles.
\end{abstract}

\section{INTRODUCTION}

Current interest in ferroelectric thin films results from the numerous potential applications for these materials which utilize the unique dielectric, pyroelectric, electro-optic, acousto-optic, and piezo-electric properties of ferroelectrics materials 1 . The synthesis of thin films of the lead-based ferroelectrics, $\mathrm{PbTiO}_{3}$, $\mathrm{Pb}\left(\mathrm{Zr}_{\mathrm{x}} \mathrm{Ti}_{1-\mathrm{x}}\right) \mathrm{O}_{3}$ (PZT), $\left(\mathrm{Pb}_{1-\mathrm{x}} \mathrm{La}_{\mathrm{x}}\right)\left(\mathrm{Zr}_{\mathrm{y}} \mathrm{Ti}_{1-\mathrm{y}}\right) \mathrm{O}_{3}$ (PLZT), etc., using a variety of techniques (e. g., sol-gel, sputtering, laser ablation, MOCVD) and the resulting properties of the films have been studied extensively 1 . For many applications, such as non-volatile dynamic random access memory (DRAM) or electro-optic waveguide modulators, a highly textured microstructure is preferable or essential. Ferroelectric film deposition using MOCVD has been widely reported and has been shown to be able to produce film microstructures from random polycrystalline to highly epitaxial ${ }^{2}$. Devices fabricated from single-crystal films with low defect density could potentially take full advantage of the tensor nature of the anisotropic properties 
of ferroelectric materials, resulting in improved device performance and enhanced device characteristics. In addition, for applications such as optical waveguide modulators, waveguide frequency doublers and Surface Acoustic Wave (SAW) delay lines, the high degree of structural perfection in such epitaxial films could substantially reduce propagation losses associated with grain boundary scattering to levels where the total insertion losses are sufficiently low (i. e., $<1.0 \mathrm{~dB} / \mathrm{cm}$ ) for feasible device applications.

We have systematically studied the effects of gas phase composition, substrate materials, substrate orientation, and deposition temperature on the phase, composition, crystallinity, morphology and domain structure of epitaxial thin films of $\mathrm{PbTiO}_{3}{ }^{3-5}$. We have also discussed the effects of the choice of substrate material on the crystallinity, microstructure, domain formation, defect structure and optical properties of $\mathrm{PbTiO}_{3}$ thin films 6-7. In this paper, we report results on the growth, characterization and properties of $\mathrm{Pb}\left(\mathrm{Zr}_{0.35} \mathrm{Ti}_{0.65}\right) \mathrm{O}_{3}, \mathrm{~Pb}\left(\mathrm{Zr}_{0.65} \mathrm{Ti}_{0.35}\right) \mathrm{O}_{3}$ and $\mathrm{PbTiO}_{3}$ thin films deposited on $\mathrm{SrRuO}_{3}$ buffered $\mathrm{SrTiO}_{3}(100)$ and $\mathrm{MgO}(100)$ substrates using MOCVD. These results demonstrate that near single-crystal-like structure and dielectric properties can be achieved in epitaxial PZT thin film multilayer structures.

\section{EXPERIMENTAL}

Epitaxial $\mathrm{SrRuO}_{3}$ thin films were deposited on epitaxial-grade (100) $\mathrm{SrTiO}_{3}$ and $\mathrm{MgO}$ (100) substrates by $90^{\circ}$ off-axis, RF magnetron sputtering at a growth pressure of $15 \mathrm{~Pa}$ and deposition temperature of $650^{\circ} \mathrm{C}$. Sputter deposition commenced at a power of $60 \mathrm{~W}$ and a $\mathrm{Ar} / \mathrm{O}_{2}$ flow rate of $120 / 80 \mathrm{sccm}$. The growth rate of the $\mathrm{SrRuO}_{3}$ layers was estimated from $\mathrm{RBS}$ to be $\sim 160 \AA$ per hour. For $\mathrm{MgO}$ (100) substrates, the same growth conditions were used, however, an additional $\mathrm{BaTiO}_{3}(100)$ buffer.layer was used between the $\mathrm{SrRuO}_{3}$ and the $\mathrm{MgO}$ substrate to improve the crystallinity of the $\mathrm{SrRuO}_{3}{ }^{8}$.

PZT and PT thin film depositions were carried out in a low pressure, horizontal, cold wall reactor with a resistive substrate heater. The. $\mathrm{SrRuO}_{3}$ buffered $\mathrm{SrTiO}_{3}(100)$ and $\mathrm{MgO}(100)$ were used as the substrate materials. Tetraethyl lead, $\mathrm{Pb}\left(\mathrm{C}_{2} \mathrm{H}_{5}\right)_{4}$, zirconium $\mathrm{t}$-butoxide, $\mathrm{Zr}\left(\mathrm{OC}\left(\mathrm{CH}_{3}\right)_{3}\right)_{4}$, and titanium isopropoxide, $\mathrm{Ti}\left(\mathrm{OC}_{3} \mathrm{H}_{7}\right)_{4}$, (Morton International, Advanced Materials, Danvers, MA) were chosen as the metal ion precursors. UHP (99.9995\%) $\mathrm{N}_{2}$ and $\mathrm{O}_{2}$ were used as the carrier gas and the oxidant, respectively. Details of the reactor design and deposition methods have been previously reported ${ }^{3-7,9}$. The growth conditions for deposition of $\mathrm{PbTiO}_{3}, \mathrm{~Pb}\left(\mathrm{Zr}_{0.35} \mathrm{Ti}_{0.65}\right) \mathrm{O}_{3}$ and $\mathrm{Pb}\left(\mathrm{Zr}_{0.65} \mathrm{Ti}_{0.35}\right) \mathrm{O}_{3}$ are shown in Table I.

The crystallinity, domain structure and chemical composition of the $\mathrm{PbTiO}_{3}$ films were investigated with $x$-ray diffraction (XRD) analysis. X-ray $\theta-2 \theta$ diffraction and $\theta$-rocking spectra of the films were obtained using a Rigaku diffractometer and a $15 \mathrm{~kW} \mathrm{Cu}_{\alpha}$ rotating anode $\mathrm{x}$-ray source. The angular resolution of this system is $2 \theta \& \theta>0.10^{\circ}, \chi \sim 3.5^{\circ}$. Crystallographic analysis and off-specular XRD was performed using a $12 \mathrm{~kW} \mathrm{CuK \alpha}$ rotating anode $\mathrm{x}$-ray source focused by a bent graphite monochromator to the center of a four-circle.Huber spectrometer. A two-circle stage with a second graphite analyzer was mounted on the $2 \theta \mathrm{arm}$. The angular resolution of this system is $2 \theta \& \theta \sim 0.15^{\circ}, \phi \sim 0.17-0.50^{\circ}, \chi \sim 0.9-1.5^{\circ}$. A detailed description of this 6-circle XRD system and its application to the study of epitaxial thin films is given elsewhere ${ }^{10}$. Descriptions of the TEM sample preparation and methods have been previously reported ${ }^{3-4}$. The RBS and channeling methods as well as details of the ion-channeling apparatus have been described previously 11 . Prism-coupling waveguide experiments were performed with a Metricon 2010 Prism-Film 
TABLE I. GROWTH CONDITIONS

\begin{tabular}{|c|c|}
\hline Substrate temperature & $700^{\circ} \mathrm{C}$ \\
\hline Reactor pressure & 8 torr \\
\hline OM precursor temperature & $\begin{array}{lll}\mathrm{Ti}\left(\mathrm{OC}_{3} \mathrm{H}_{7}\right)_{4} & - & 39-40^{\circ} \mathrm{C} \\
\mathrm{Pb}\left(\mathrm{C}_{2} \mathrm{H}_{5}\right)_{4} & - & 27-28^{\circ} \mathrm{C} \\
\mathrm{Zr}\left(\mathrm{OCCH}_{3}\right)_{4} & - & 29-30^{\circ} \mathrm{C}\end{array}$ \\
\hline OM precursor pressure & $\begin{array}{llr}\mathrm{Ti}\left(\mathrm{OC}_{3} \mathrm{H}_{7}\right)_{4} & - & 37 \text { torr } \\
\mathrm{Pb}\left(\mathrm{C}_{2} \mathrm{H}_{5}\right)_{4} & - & 150 \text { torr } \\
\mathrm{Zr}\left(\mathrm{OC}\left(\mathrm{CH}_{3}\right)_{3}\right)_{4}- & 400 \text { torr } \\
\end{array}$ \\
\hline Flow rate of reactant gas $\left(\mathrm{O}_{2}\right)$ & $200 \mathrm{sccm}$ \\
\hline $\begin{array}{l}\text { Flow rate of } \mathrm{OM} \text { and carrier gas }\left(\mathrm{N}_{2}\right) \\
\mathrm{PbTiO}_{3}\end{array}$ & $\begin{array}{lrr}\mathrm{Ti}\left(\mathrm{OC}_{3} \mathrm{H}_{7}\right)_{4} & - & 50 \mathrm{sccm} \\
\mathrm{Pb}\left(\mathrm{C}_{2} \mathrm{H}_{5}\right)_{4} & - & 35 \mathrm{sccm} \\
\mathrm{Zi}\left(\mathrm{OC}\left(\mathrm{CH}_{3}\right)_{3}\right)_{4}- & 0 \mathrm{sccm} \\
\end{array}$ \\
\hline $\begin{array}{l}\text { Flow rate of } \mathrm{OM} \text { and carrier gas }\left(\mathrm{N}_{2}\right) \\
\mathrm{Pb}\left(\mathrm{Zr}_{0.35} \mathrm{Ti}_{0.65}\right) \mathrm{O}_{3}\end{array}$ & $\begin{array}{lll}\mathrm{Ti}\left(\mathrm{OCC}_{3} \mathrm{H}_{7}\right)_{4} & - & 35 \mathrm{sccm} \\
\mathrm{Pb}\left(\mathrm{C}_{2} \mathrm{H}_{5}\right)_{4} & - & 50 \mathrm{sccm} \\
\mathrm{Zr}\left(\mathrm{OCC}\left(\mathrm{CH}_{3}\right)_{3}\right)_{4}- & 25 \mathrm{sccm}\end{array}$ \\
\hline $\begin{array}{l}\text { Flow rate of } \mathrm{OM} \text { and carrier gas }\left(\mathrm{N}_{2}\right) \\
\mathrm{Pb}\left(\mathrm{Zr}_{0.65} \mathrm{Ti}_{0.35}\right) \mathrm{O}_{3}\end{array}$ & $\begin{array}{lll}\mathrm{Ti}\left(\mathrm{OCC}_{3} \mathrm{H}_{7}\right)_{4} & - & 35 \mathrm{sccm} \\
\mathrm{Pb}\left(\mathrm{C}_{2} \mathrm{H}_{5}\right)_{4}: & - & 50 \mathrm{sccm} \\
\mathrm{Zr}\left(\mathrm{OC}_{(}\left(\mathrm{CH}_{3}\right)_{3}\right)_{4}- & 25 \mathrm{sccm}\end{array}$ \\
\hline Flow rate of background gas $\left(\mathrm{N}_{2}\right)$ & $600 \mathrm{sccm}$ \\
\hline Film thickness & $0.2-1.0 \mu \mathrm{m}$ \\
\hline Film growth rate & $40 \AA /$ min. \\
\hline Substrates & $\begin{array}{l}\mathrm{SrRuO}_{3} / \mathrm{SrTiO}_{3}(100) \\
\mathrm{SrRuO}_{3} / \mathrm{BaTiO}_{3} / \mathrm{MgO}(100)\end{array}$ \\
\hline
\end{tabular}

coupler using a HeNe laser $(632.8 \mathrm{~nm})$; this system has been described elsewhere9. Ferroelectric hysteresis, bipolar resistance, dielectric fatigue, and dielectric breakdown measurement were obtained using a Radiant Technologies RT6000HVS tester.

\section{RESULTS AND DISCUSSION}

Epitaxial metallic oxide. layers have been show to yield enhanced device performance due to their excellent chemical and structural compatibility with many oxide materials ${ }^{12}$. The growth of $\mathrm{SrRuO}_{3}$ and other conductive oxide thin films for use as buffer layers and epitaxial electrodes has shown great promise in the field of integrated ferroelectrics because of the significant improvement in fatigue characteristic of capacitors formed using these electrodes ${ }^{13}$. In Fig. 1, we show the results of four-circle XRD on an epitaxial $\mathrm{SrRuO}_{3}$ thin film deposited on $\mathrm{SrTiO}_{3}(100)$ by $\mathrm{RF}$ sputtering. The thickness of the layer was $\sim 330 \AA$ determined by RBS and TEM measurements. In Fig. 1a, we show the specular $\theta-2 \theta$ scan. In addition to the $\mathrm{SrTiO}_{3}(100)$ and (200) substrate reflections, the only observable reflections correspond to $\mathrm{SrRuO}_{3}(100)$ and (200). The $\theta$-rocking curves for $\mathrm{SrTiO}_{3}(100)$ and $\mathrm{SrRuO}_{3}(200)$ are show in Fig. 1b; the full width at half maximum (FWHM) of the $\mathrm{SrRuO}_{3}(200)$ reflection, which determines that the crystalline mosaic spread of 

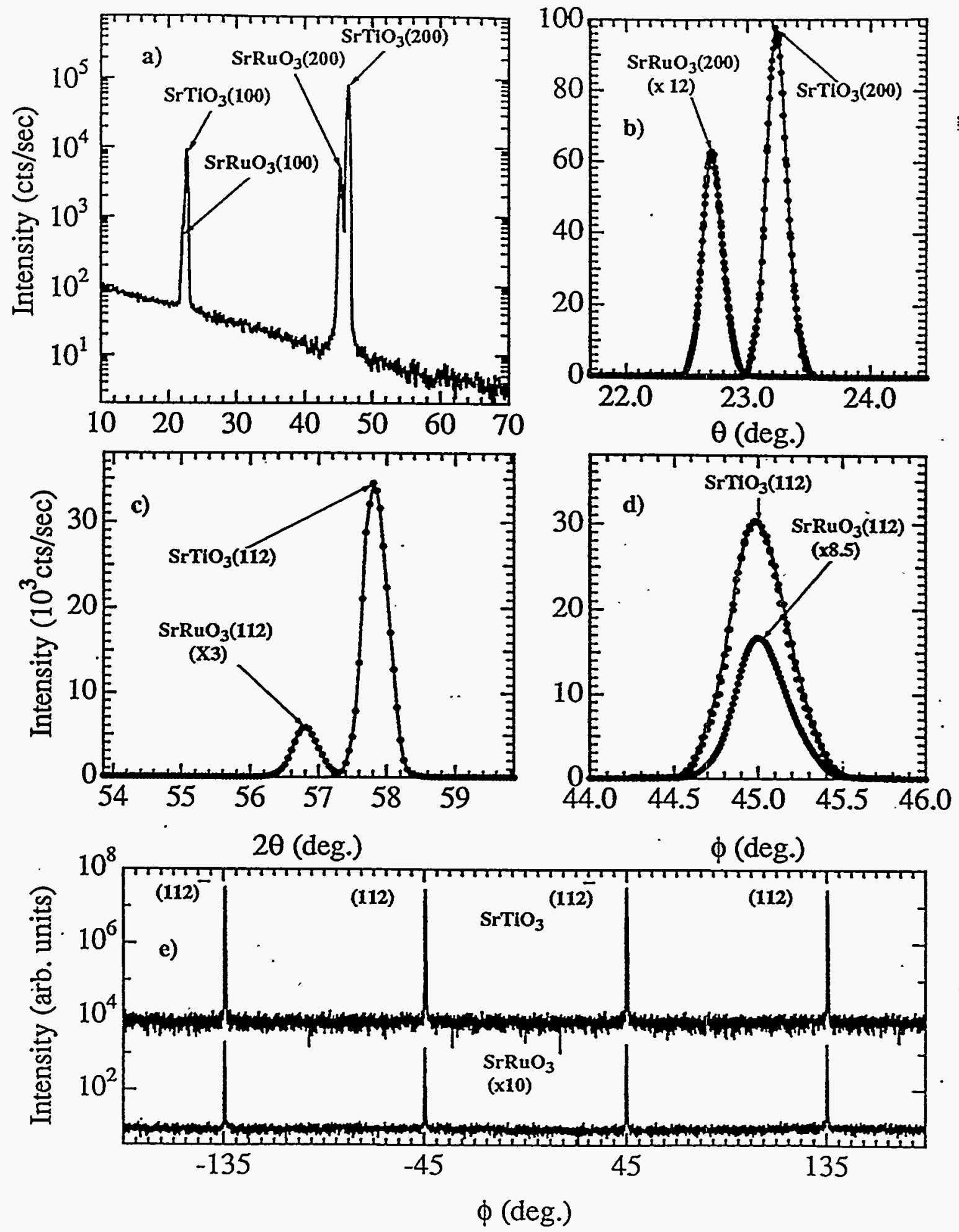

Figure 1: $\mathrm{XRD}$ data for a $\mathrm{SrRuO}_{3}$ thin film deposited on $\mathrm{SrTiO}_{3}(100)$ by $\mathrm{RF}$ sputtering: a) specular $\theta-2 \theta$ scan, b) $\theta$-rocking of $\mathrm{SrRuO}_{3}(200)$ and $\mathrm{SrTiO}_{3}(200)$, c) offspecular $\theta-2 \theta$ scan of $\mathrm{SrRuO}_{3}(112)$ and $\mathrm{SrTiO}_{3}$ (112), d) detailed $\phi$-scan of $\mathrm{SrRuO}_{3}(112)$ and $\mathrm{SrTiO}_{3}(112)$, e) $360^{\circ} \phi$-scans. 
the growth plane, is $\sim 0.15^{\circ}$ (instrument resolved) and is comparable to that of the substrate reflection. Fig. Ic and $1 d$, show the off-specular $\theta-2 \theta$ scan and $\phi$-scans, respectively, of the $\mathrm{SrTiO}_{3}(112)$ and $\mathrm{SrRuO}_{3}(112)$ reflections. In Fig. 1c, the presence of the $\mathrm{SrRuO}_{3}$ (112) reflection oriented with respect to the $\mathrm{SrTiO}_{3}(112)$ reflection indicates the single crystal nature of the film and determines the in-plane epitaxial relationship between the film and the substrate: (100)[010] $\mathrm{SrRuO}_{3} / /(100)[010] \mathrm{SrTiO}_{3}$. As shown in the $360^{\circ} \phi$-scans (Fig. 1e), this in-plane epitaxial relationship is reflected in the mapping of the four-fold symmetry of the $\mathrm{SrTiO}_{3}(112)$ family of reflections (upper curve; $\mathrm{K}$ positive) onto the $\mathrm{SrRuO}_{3}(112)$ family of reflections (lower curve). Since the Bragg reflections were sharp, well defined peaks, we performed a refinement of the lattice constants of the $\mathrm{SrRuO}_{3}$ film. Using the following $\mathrm{x}$-ray reflections: $\mathrm{SrRuO}_{3}(002),(112),(\overline{1} 12),(1 \overline{1}$ 2), ( $(\overline{11} 2),(022),(202),(0 \overline{2} 2),(\overline{2} 02),(013),(103),(0 \overline{1} 3)$, and ( $\overline{1} 03)$, we obtained lattice constants for the film of $a=b=c=3.9400 \pm 0.001 \AA, \alpha=\beta=\gamma=90.000 \pm 0.001^{\circ}$ at room temperature. While the established crystal structure for $\mathrm{SrRuO}_{3}$ is orthorhombic ${ }^{14}$, the distortion of the cubic perovskite lattice is very small and our data corresponds well to the pseudo-cubic perovskite structure. The in-plane crystalline mosaic in the film is $\sim 0.45^{\circ}$, which is determined from the FWHM of the $\phi$-scans of the $\mathrm{SrRuO}_{3}(112)$. reflection (Figs. 1d); the $\phi$-scan of the $\mathrm{SrTiO}_{3}(112)$ is shown for reference.

Using these $\mathrm{SrRuO}_{3}$ thin films as bottom electrodes, epitaxial $\mathrm{Pb}\left(\mathrm{Zr}_{\mathrm{x}} \mathrm{Ti}_{1-\mathrm{x}}\right) \mathrm{O}_{3}(\mathrm{PZT} ; \mathrm{x}=0,0.35 ; 0.65)$. thin films were deposited layers on $\mathrm{SrTiO}_{3}(100)$ and $\mathrm{MgO}(100)$ substrates by MOCVD. Using the growth conditions specified in Table I, the films produced were pure perovskite phase with a single-crystalline structure. Shown in Fig. 2 is the XRD. data for two compositions of PZT films. grown on epitaxial $\mathrm{SrRuO}_{3}(100)$ buffered $\mathrm{SrTiO}_{3}(100)$ : PZT(0/100) [Fig. 2a, $\theta-2 \theta$; Fig. 2b; $\theta$-rocking for the (001) reflection; Fig. 2c, $\theta$-rócking rocking for the (100) reflection] and PZT(35/65) [Fig. 2d, $\theta-2 \theta$; Fig. 2e, $\theta$-rocking rocking for the (002) reflection; Fig. 2f, $\theta$-rocking rocking for the (200) reflection]. From the $\theta-2 \theta$ scans; Fig. $2 \mathrm{a}$ and $2 \mathrm{~d}$, we determine that the films have nominal compositions of $\mathrm{PbTiO}_{3}$ and $\mathrm{Pb}\left(\mathrm{Zr}_{0.35} \mathrm{Ti}_{0.65}\right) \mathrm{O}_{3}$, respectively, and are highly $c$-axis oriented. We. have previously demonstrated that the presence of the $\mathrm{PZT}(0 / 100)$ and PZT(35/65) (100) reflections in the $\theta-2 \theta$ scans results from the presence of $90^{\circ}$ domains ( $a$ axis) in the films ${ }^{6}$. In addition, the films are epitaxial grown with respect to both the $\mathrm{SrRuO}_{3}$ layer and the substrate. The $\theta$-rocking of the PZT(0/100) (001) reflection (Fig. 2b), shows the presence of shoulders and consists of multiple peaks. This splitting arises as a result of the geometric and strain accommodation of the film when $90^{\circ}$ domains are formed ${ }^{15-16}$. The $\theta$-rocking of the PZT(35/65) (002) reflection (Fig. 2e), shows no splitting due to the better lattice mismatch and lower tetragonality of this composition combined with insufficient instrument resolution. The full width at half maximum for the PZT(0/100) (100), Fig. 2c, and PZT(35/65) (200), Fig. 2f, are $0.75^{\circ}$ and $0.93^{\circ}$, respectively. From the integrated intensity ratio of the PZT(35/65) (002) and (200) reflections and the PZT(0/100) (001) and (100) reflections, we determine that the films contain a volume fraction of $90^{\circ}$ domains of $\sim 7 \%$ and $\sim 29 \%$, respectively.

Shown in Fig. 3 is the XRD data for two compositions of PZT films grown on epitaxial $\mathrm{SrRuO}_{3}(100) / \mathrm{BaTiO}_{3}(001)$ buffered $\mathrm{MgO}(100)$ : $\mathrm{PZT}(35 / 65)$ [Fig. 3a, $\theta-2 \theta$; Fig. 3b, $\theta$-rocking for the (002) reflection; Fig. 3c, $\theta$-rocking rocking for the (200) reflection] and PZT(65/63) [Fig. 3d, $\theta-2 \theta$; Fig. $3 e, \theta$-rocking rocking for the (001) reflection]. From Fig. 3a-3c, we see that PZT(35/65) films grown on the buffered $\mathrm{MgO}$ substrates are quite similar structurally to those deposited on buffered $\mathrm{SrTiO}_{3}$ (Figs. 2d-2f); however, with a slightly higher volume fraction of $90^{\circ}$ domains of $\sim 31 \%$. From the $\theta-2 \theta$ scan of the PZT(65/35) film, we can see that the (001) and (100) reflections have merged indicating that the film has the 

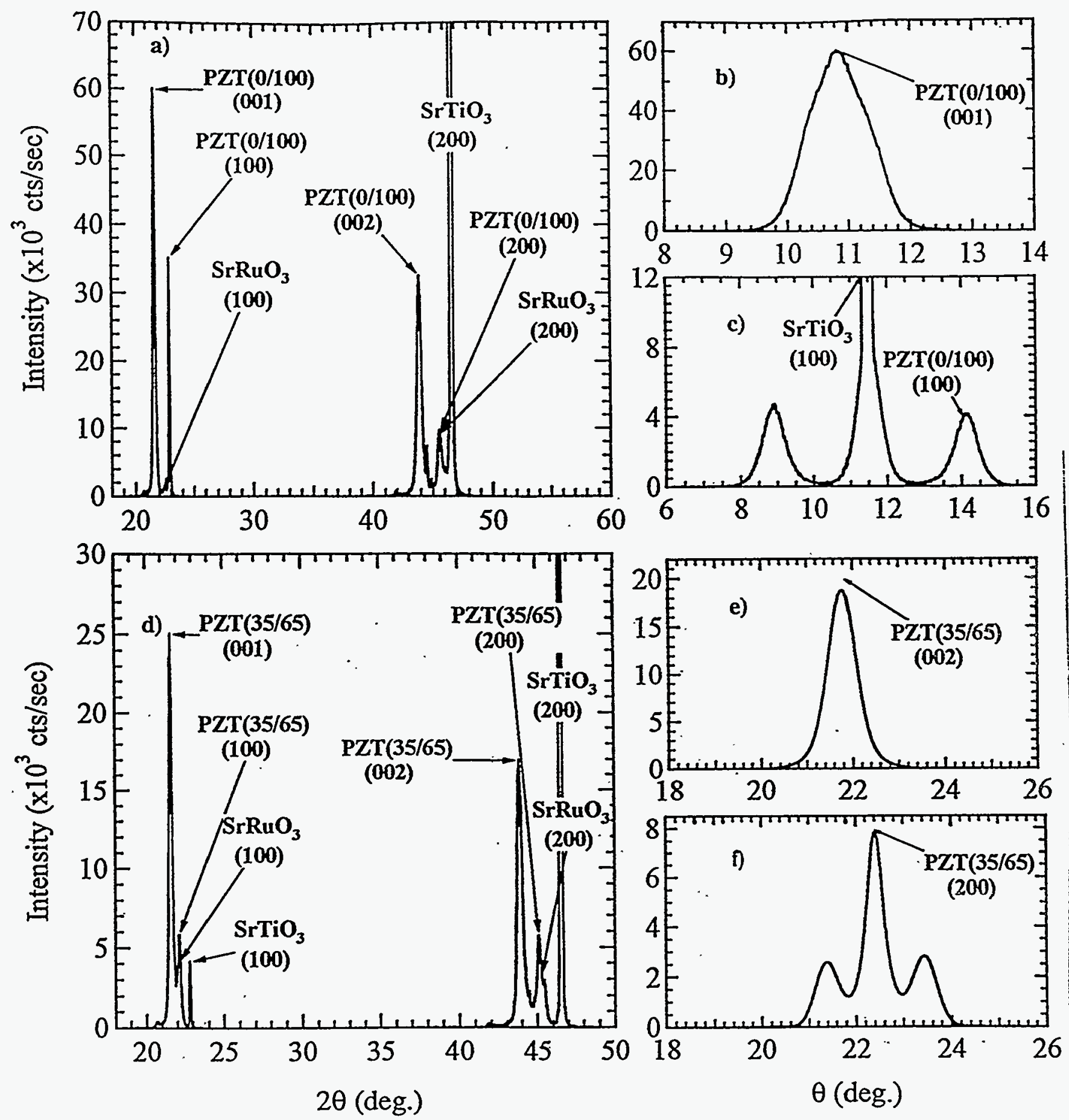

Figure 2. XR.D data for two compositions of PZT films grown on epitaxial $\mathrm{SrRuO}_{3}(100)$ buffered $\mathrm{SrTiO}_{3}(100): \operatorname{PZT}(0 / 100)$ [Fig. 2a, $\theta-2 \theta$; Fig. 2b, $\theta$-rocking for the (001) reflection; Fig. 1c, $\theta$-rocking rocking for the (100) reflection] and PZT(35/65) [Fig. 2d, $\theta-2 \theta$; Fig. 2e, $\theta$-rocking rocking for the (002) reflection; Fig. 2f, $\theta$-rocking rocking for the (200) reflection].

rhombohedral structure expected for this composition, and is (001) pseudo-cubic oriented (i. e., (012) rhombohedral); however, FWHM of the rocking curve of the PZT(65/35) (100) reflections is broad, $\sim 1.6^{\circ}$, indicating that the degree of orientation of this film is poorer than that of tetragonal compositions. 

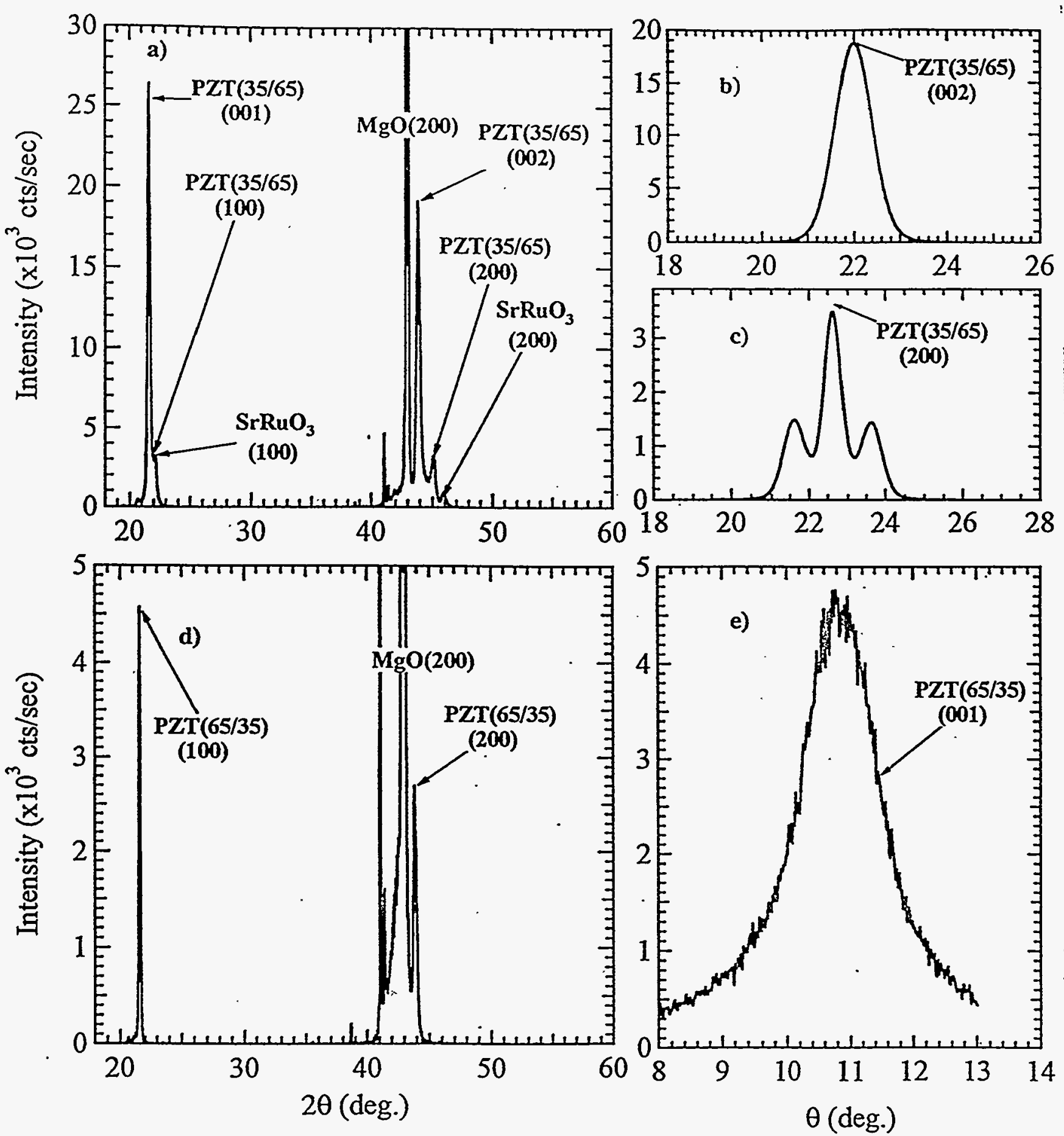

Figure 3. XRD data for two compositions of PZT films grown on epitaxial $\mathrm{SrRuO}_{3}(100) / \mathrm{BaTiO}_{3}(001)$ buffered $\mathrm{MgO}(100)$ : PZT(35/65) [Fig. 3a, $\theta-2 \theta$; Fig. 3b, $\theta$-rocking for the (002) reflection; Fig. 3c, $\theta$ rocking rocking for the (200) reflection] and PZT(65/63) [Fig. 3d, $\theta-2 \theta$; Fig. 3e, $\theta$-rocking rocking for the (001) reflection].

In Fig. 4a, we show the results of $\mathrm{RBS}$ channeling measurements on the $\mathrm{Pb}\left(\mathrm{Zr}_{0.35} \mathrm{Ti}_{0.65}\right) \mathrm{O}_{3}$ grown directly on $\mathrm{SrTiO}_{3}(100)$, the maximum channeling yield reduction at the $\mathrm{Pb}$ signal is $\sim 71 \%$. The inset of Fig. 4a shows the angular channeling width; the full width at half minimum is $\sim 1.6^{\circ}$. In fig. $2 b$, we show the RBS 

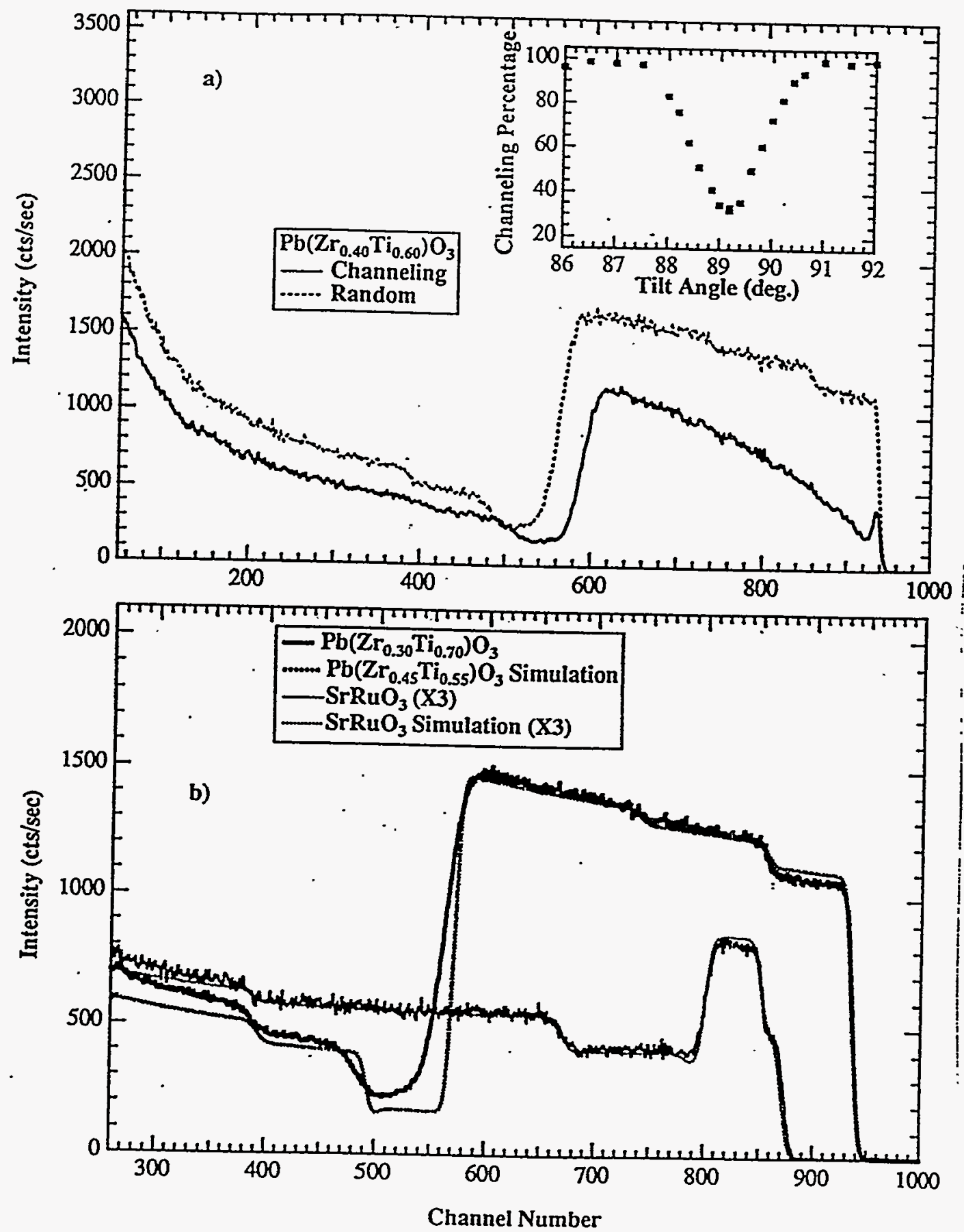

Figure 4. a) RBS channeling results for an epitaxial $\mathrm{Pb}\left(\mathrm{Zr}_{0.35} \mathrm{Ti}_{0.65}\right) \mathrm{O}_{3}$ thin film grown on $\mathrm{SrTiO}_{3}(100)$. The inset shows the angular channeling width. b) RBS data and simulation results for epitaxial $\mathrm{Pb}\left(\mathrm{Zr}_{0.35} \mathrm{Ti}_{0.65}\right) \mathrm{O}_{3}$ and $\mathrm{SrRuO}_{3}$ thin films grown on $\mathrm{SrTiO}_{3}(100)$.

data and simulations of the RBS data for a $\mathrm{Pb}\left(\mathrm{Zr}_{0.35} \mathrm{Ti}_{0.65}\right) \mathrm{O}_{3}$ film grown directly on $\mathrm{SrTiO}_{3}(100)$ and a $\mathrm{SrRuO}_{3}$ film grown on $\mathrm{SrTiO}_{3}(100)$. The simulation for the $\mathrm{SrRuO}_{3}$ film indicates that the films is pure stoichiometric $\mathrm{SrRuO}_{3}$ with a thickness of $\sim 330 \AA$. The simulation of the PZT film was less successful. The 
best fit was obtained for a composition of PZT(45/55) (shown); however, the XRD and dielectric data (shown below) are more consistent with a composition of PZT(35/65); this issue remains unresolved.

In Fig. 5, we show the cross-section TEM image of a $\mathrm{PbTiO}_{3}(001) / \mathrm{SrRuO}_{3}(100) / \mathrm{SrTiO}_{3}(100)$ epitaxial film. The image shows that the films is epitaxial $c$-axis oriented, with $90^{\circ}$ domains and threadingdislocations being the primary structural defects. The thickness of the $\mathrm{SrRuO}_{3}$ layer is $\sim 330 \AA$. Note that the $90^{\circ}$ domain visible in the image clearly nucleates at structural defects in the substrate. The strain contrast associated with the substrate defect site appears to propagate directly through the $\mathrm{SrRuO}_{3}$ layer into the $\mathrm{PbTiO}_{3}$ layer. In addition, in lower magnification images, we observed threading dislocations that appear normal to the substrate/film interface and propagate through the $90^{\circ}$ domains. Presumably, this would indicate that these dislocations form prior to the ferroelectric phase transition while the films is in the cubic state. The $\mathrm{PbTiO}_{3}(001) / \mathrm{SrRuO}_{3}(100) / \mathrm{SrTiO}_{3}(100)$ interfaces shown in Fig. 5 are atomically sharp; note that the $\mathrm{PbTiO}_{3}(001) / \mathrm{SrRuO}_{3}(100)$ interface appears. to be cleaner that the $\mathrm{SrRuO}(100) / \mathrm{SrTiO}_{3}(100)$ interface indicating that the deposition of the buffer layer appears to improve the quality of the substrate surface resulting in an improved ferroelectric film. The selected area electron diffraction pattern of the interface structure is shown as a inset to Fig. 5. This pattern determined the epitaxial relationships between the $\mathrm{PbTiO}_{3}$ and $\mathrm{SrRuO}_{3}$ films and the $\mathrm{SrTiO}_{3}$ substrate: $(100)[010] \mathrm{PbTiO}_{3} / /(100)[010] \mathrm{SrRuO}_{3} / /(100)[010] \mathrm{SrTiO}_{3}$. Optical waveguiding experiments showed that the $\mathrm{Pb}\left(\mathrm{Zr}_{0.35} \mathrm{Ti}_{0.65}\right) \mathrm{O}_{3}(001)$ film, had high ordinary refractive index of 2.5811 at $632.8 \mathrm{~nm}$.

Shown in Fig. 6 are the results of polarization hysteresis (i. e., P-E curve) and polarization fatigue measurements of our PZT films. Fig. 5a shows the P-E curve for a $\mathrm{Ag} / \cdot \mathrm{PZT}(35 / 65)(001) / \mathrm{SrRuO}_{3}(100)$ $\mathrm{SrTiO}_{3}(100)$ capacitor. The results of these measurement are: a remanent polarization of $46.2 \mu \mathrm{C} / \mathrm{cm}^{2}$, the saturation polarization of $55.1 \mu \mathrm{C} / \mathrm{cm}^{2}$, a coercive field of $54.9 \mathrm{kV} / \mathrm{cm}$, and a bipolar resistivity of $>5.8 \times 10^{9}$ $\Omega-\mathrm{cm}$ at $275 \mathrm{kV} / \mathrm{cm}$. The dielectric breakdown strength of this capacitor was $>400 \mathrm{kV} / \mathrm{cm}$ (this field strength was the limit of our instrument). The dielectric constant of this films at $1 \mathrm{Mhz}$ was 410 . The electrical measurements indicate that the properties of this film are a significant fraction of those of bulk material (e. $g$., $\sim 70 \%$ of the single crystal remanent polarization). However, we measured a volume fraction. of $90^{\circ}$ domains of $-30 \%$. If we assume that only a small portion of this twin volume undergoes $90^{\circ}$ switching, then this volume fraction of the film will not contribute to the measured remanent polarization; consequently, the true remanent polarization could be as high as $\sim 60 \mu \mathrm{C} / \mathrm{cm}^{2}$, very close to that of the bulk material at this composition. Fig. 5b shows the P-E curve for a $\mathrm{Ag} / \mathrm{PZT}(65 / 35)(001) / \mathrm{SrRuO}_{3}(100) / \mathrm{SrTiO}_{3}(100)$ capacitor. The results of these measurement are: a remanent polarization of $16.8 \mu \mathrm{C} / \mathrm{cm}^{2}$, the saturation polarization of $20.4 \mu \mathrm{C} / \mathrm{cm}^{2}$, a coercive field of $42.5 \mathrm{kV} / \mathrm{cm}$, and a bipolar resistivity of $>1.5 \times 10^{10} \Omega-\mathrm{cm}$ at $150 \mathrm{kV} / \mathrm{cm}$. The dielectric breakdown strength of this capacitor was $>250 \mathrm{kV} / \mathrm{cm}$ (this field strength was the limit of our instrument). The dielectric constant of this films at $1 \mathrm{Mhz}$ was 305. As show above, this film is (001) oriented; however, for thombohedral compositions of PZT, the polarization axis is along the (111) pseudocubic direction. If we include this geometric factor, our actual remanent polarization along the (111) direction is $29.1 \mu \mathrm{C} / \mathrm{cm}^{2}$. In addition, even though the fraction of ferroelectric domains in the material, unlike for tetragonal compositions, could not be measured by simple XRD, the films must contain some volume fraction of such material. These twins will also reduce the measured polarization values. In Fig. 5c, we show the result of polarization fatigue measurements of two $\mathrm{Ag} / \mathrm{PZT}(65 / 35)(001) / \mathrm{SrRuO}_{3}(100) / \mathrm{SrTiO}_{3}(100)$ capacitors in series. This data was taken at a pulse rate of $10 \mathrm{kHz}$ and $15 \mathrm{~V}$. That data indicate that the 


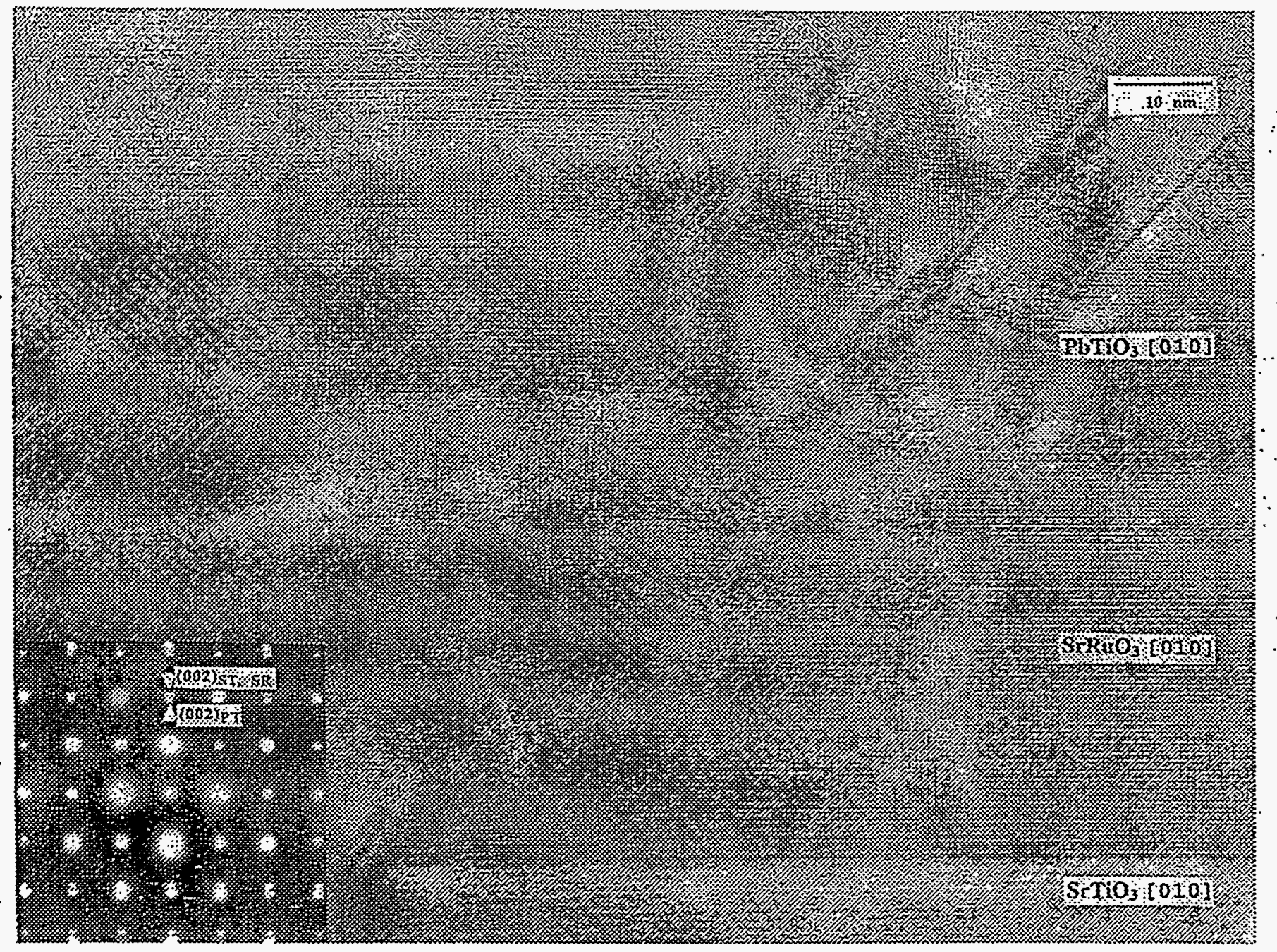

Figure 5. High resolution cross-sectional TEM image of the $\mathrm{PbTiO}_{3}(001) / \mathrm{SrRuO}_{3}(100) / \mathrm{SrTiO}_{3}(100)$ interfaces showing that the individual layer interfaces are atomically sharp. The dominate defects in the film a $90^{\circ}$ domains and threading dislocations. The inser shows the selected area electron diffration pautern of the interface region. 

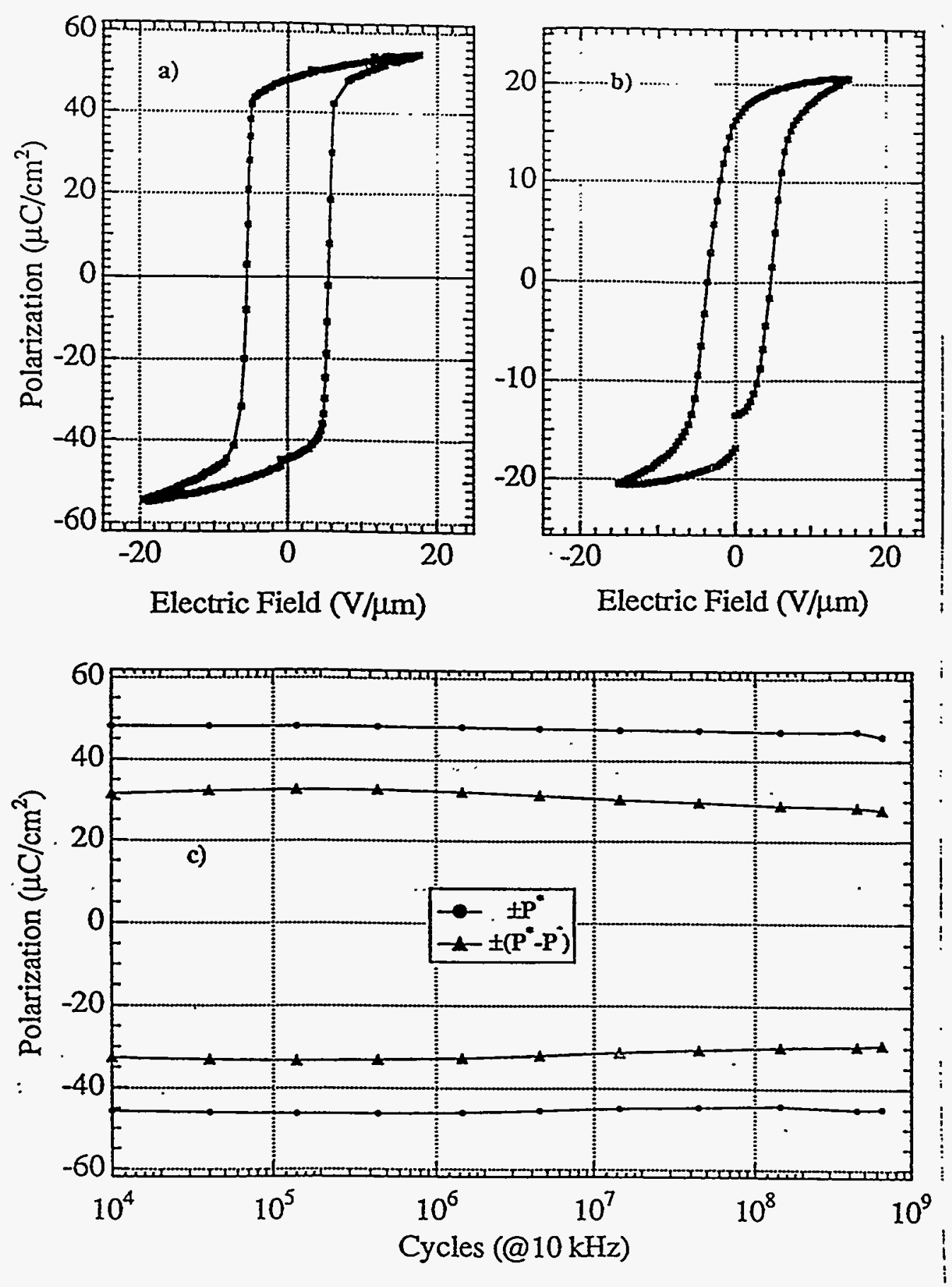

Figure 6. a) The ferroelectric polarization $\mathrm{P}$-E hysteresis curve for a $\mathrm{Ag} / \mathrm{Pb}\left(\mathrm{Zr}_{0.35} \mathrm{Ti}_{0.65}\right) \mathrm{O}_{3}(001)$ $/ \mathrm{SrRuO}_{3}(100) / \mathrm{SrTiO}_{3}(100)$ capacitor. The ferroelectric polarization P-E hysteresis curve b) and polarization fatigue data c) for a $\mathrm{Ag} / \mathrm{Pb}\left(\mathrm{Zr}_{0.65} \mathrm{Ti}_{0.35}\right) \mathrm{O}_{3}(001) / \mathrm{SrRuO}_{3}(100) / \mathrm{SrTiO}_{3}(100)$ capacitor.

materials showed little fatigue out to $10^{9}$ cycles. We note that the growth conditions for these PZT films have not been optimized and, in principle, improvements in the films crystallinity and properties could be achieved. These results indicate that through the use of epitaxial buffer layers and electrode materials, very high structural perfection can be achieved with commensurate bulk-like properties in epitaxial ferroelectric films. 


\section{ACKNOWLEDGMENTS}

This work was supported by the U. S. Department of Energy, Basic Energy Science-Materials Science through contract \#W-31-109-ENG-38 under the joint CRADA with Hewlett-Packard Company \#C9301701.

\section{REFERENCES}

1. For example see, Ferroelectric Thin Films III, ed. E. R. Myers, B. A. Tuttle, S. B. Desu, and P. K. Larsen, (Mat. Res. Soc. Symp. Proc. Vol. 310, San Francisco, CA 1993).

2. C. J. Brierley, C. Trundle, L. Considine, R. W. Whatmore, and F. W. Ainger, Ferroelectrics 90,181 (1989); A. I. Kingon, K. Y. Hsieh, L. L. King, S. H. Rou, K. J. Backmann, and R. F. Davis, in Ferroelectric Thin Films, ed. by E. R. Myers and A. I. Kingon, (Mat. Res. Soc. Symp. Proc. Vol. 200, Pittsburg, PA 1990); T. Katayama, M. Fuzimoto, M. Shimizu, and T. Shiosaki, Jpn. J. Appl. Phys. 30, 2189 (1991).

3. G. R. Bai, H. L. M. Chang, H. K. Kim, C. M. Foster, and D. J. Lam, Appl. Phys. Lett 64, 408 (1992); Y. Gao, G. Bai, K. L. Merkle, Y. Shi, H. L. M. Chang, Z. Shen, and D. J. Lam, J. Mater. Res. 8, 145 (1993).

4. G. R. Bai, H. L. M. Chang, C. M. Foster, Z. Shen, and D. J. Lam, J. Mater. Res. 9, 156 (1994).

5. H. You, H. L. M. Chang, R. P. Chiarello, and D. J. Lam, in Heteroepitaxy of Dissimilar Materials, ed. by R. F. C. Ferrow, J. P. Harbison, P. S. Peercy, and A. Zangwill (Mat. Res. Soc. Symp. Proc. Vol. 221, Pittsburg, PA 1990) p. 181.

6. C. M. Foster, Z. Li, G. R. Bai, H. You, D. Guo, and H. L. M. Chang, in Epitaxial Oxide Thin Films and Heterostructures, ed. D. K. Fork, J. M. Phillips, R. Ramesh, and R. M. Wolf, (Mat. Res. Soc. Symp. Proc. Vol. 341, San Francisco, CA 1994).

7. C. M. Foster, Z. Li, M. Buckett, D. Miller, P. M. Baldo, L. E. Rehn, G. R. Bai, D. Guo, H. You and K. L. Merkle, (submitted to J. Appl. Phys.).

8. L. A. Wills and J. Amano, in Ferroelectric Thin Films IV (this work), presented at the 199.4 Fall MRS Meeting, Boston, MA 1994).

9. C. M. Foster, S.-K. Chan, H. L. M. Chang, R. P. Chiarello, T. J. Zhang, J. Guo, and D. J. Lam, J. Appl. Phys. 73, 7823 (1993).

10. H. You, H. L. M. Chang, R. P. Chiarello, and D. J. Lam, in Heteroepitaxy of Dissimilar Materials, ed. by R. F. C. Ferrow, J. P. Harbison, P. S. Peercy, and A. Zangwill (Mat. Res. Soc. Symp. Proc. Vol. 221, Pittsburg, PA 1990) p. 181.

11. R. P. Sharma, L. E. Rehn, P. M. Baldo, and J. Z. Liu, Phys. Rev. Lett. 62, 2869 (1989).

12. C. B. Eom, J. M. Phillips and R. J. Cava, in Epitaxial Oxide Thin Films and Heterostructures, ed. D. K. Fork, J. M. Phillips, R. Ramesh, and. R. M. Wolf, (Mat. Res. Soc. Symp. Proc. Vol. 341, San Francisco, CA 1994).

13. H. N. Al-Shareef, A. I. Kingon, X. Chen, K. R. Bellur, and O. Auciello, J. Mater. Res. 11, 2968 (1994).

14. X-ray Powder Diffraction Data Card, JCPDS 43-472.

15. W. Pompe, X. Gong, Z. Suo, and J. S. Speck, J. Appl. Phys. 74 (10), 6012 (1993); J. S. Speck and W. Pompe, J. Appl. Phys. 76 (1), 466 (1994). 